\title{
First Price Auctions, Lotteries, And Risk Preferences Across Institutions
}

\author{
Russell Engel, Sacred Heart University, USA
}

\begin{abstract}
There is an unsettled debate in experimental economics literature regarding the consistency of individuals' risk preferences in varying institutions. Much of this debate stems from observations of subjects' bids in sealed-bid auctions and the implications of those bids. In this paper, I have subjects participate in a sealed-bid auction experiment and then examine if the ostensible risk parameter that one can back out from subjects' bids matches up with their elicited risk preference from a separate task in the experiment. I find that subjects do exhibit consistent risk preferences. The aggregate measure of the subjects' risk parameter is stable across both tasks, the estimated numeric values of subjects' risk parameters are stable across tasks, and the ranking of subjects (most risk averse to least risk averse) is stable across both tasks.
\end{abstract}

Keywords: Auctions; Lotteries; Risk Preferences; Laboratory Experiments

\section{INTRODUCTION}

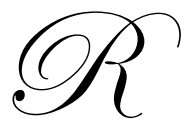

ecent experimental research has called into question the assumption that individuals who are risk averse in one institution will be risk averse in another institution. If these findings are robust, and individuals' risk preferences in one situation have no bearing on how they act in other situations, economists will face a difficult task in trying to model behavior where individuals face uncertainty. If, however, there are possibly classes of institutions, or specific features of institutions that lead to predictable behavior, the situation is much less dire.

Much of the experimental economics risk preference analysis can be traced back to Cox, Roberson and Smith (1982), and Cox, Smith and Walker (CSW) (1988). In studying first price auctions, subjects were commonly observed to bid above the risk neutral Nash equilibrium prediction. A plausible explanation is that the subjects are risk averse (Milgrom and Weber (1982)). By bidding higher, a subject increases the probability that he will win the auction, albeit at a higher price. CSW further showed that they could back out a subject's risk parameter given his bid.

Harrison (1990) put forth a challenge to the risk parameters derived by CSW. Using the BDM mechanism (Becker, Degroot, Marschak (1964)) ${ }^{1}$ and the same model as CSW, he found that his subjects' behavior was more risk loving than the behavior of CSW's subjects. It is possible that the risk parameter derived in Harrison (1990) is different than that derived by CSW simply due to having different subjects. Isaac and James (2000) explore this issue by having the same subjects participate in both an auction and a BDM experiment. On aggregate, they find that their subjects act similarly, in the first price auction, to the subjects in CSW, and that their subjects act similarly, in the BDM, to the subjects in Harrison (1990). Isaac and James (2000) calculate the risk parameter for each individual subject in both institutions, further they rank the subjects in each institution (from most to least risk averse). Their results show that neither values nor ranks are preserved across institutions. This raises a few questions. Do subjects truly have unstable parameters, or is something else at play? Do either of these devices measure risk aversion? Is the

\footnotetext{
${ }^{1}$ The BDM works as follows: a subject is endowed with a lottery, and asked his min price of selling this lottery back to the experimenter. The experimenter then draws a random number. If the number drawn is greater than the selling price, the lottery is sold and the subject receives the value of the random number. If the random number is lower than the min selling price, the subject plays the lottery and earns the proceeds.
} 
technique used to back out the risk parameter valid, is it valid for one institution and not the other?

The model used by CSW and followed by Harrison (1990) and Isaac and James (2000) assumes that individuals have constant relative risk aversion (CRRA). Kagel et al. (1987) and Smith and Walker (1993), in contradiction to this, show that as the expected payoff of winning the auction increases subjects' bids increase by more than the CRRA model would predict. Subject behavior in these studies is consistent with risk aversion, but it is increasing relative risk aversion not CRRA. ${ }^{2}$ Goeree, Holt and Palfrey (2000) explore alternatives explanations of overbidding by trying to estimate parameters with various models. They find that the risk aversion model is the best fit. So, there is strong evidence that subjects in first price auctions behave, at the least, 'as if' risk averse.

It is possible to measure this behavior without assuming either constant relative or increasing relative risk aversion. Holt and Laury (2002) introduce a new lottery device that also allows for elicitation of risk preferences. Similar to Kagel et al. and Smith and Walker, they find that subjects risk aversion increases as potential earnings increase. A nice feature of the Holt-Laury lottery is that while it can be used to get an estimate of subjects risk parameters under various assumptions of subjects' utility functions, it also allows for some proxy of risk aversion without assuming an underlying model. In my experiment, I have the same subjects participate in the first price auction and a Holt-Laury lottery. By using these institutions I can evaluate risk preferences without assuming an underlying utility function. I am also able to evaluate how well the CRRA does in measuring risk preferences across these institutions. I find that subjects behave consistently across institutions. I also find that the CRRA estimates in the first price auction are correlated with CRRA estimates derived from the lottery.

\section{EXPERIMENTAL DESIGN}

The experiment conducted for this paper was designed to elicit subjects' risk parameters in two institutions. The first institution the subjects participate in is a Holt-Laury lottery using the protocol established by Prasad and Salmon (2007). The second institution that the subjects participate in is an independent private values, first-price, sealed bid auction. All subjects participated in the lottery prior to participating in the auction. Economists are often concerned about order effects in experiments. The main concern with ordering is that participation in the first experiment will influence behavior in the subsequent experiment. This is a valid concern when the institutions are closely related (e.g. the ultimatum game and the dictator game, first price auctions and second price auctions) but that is not an issue here, the experiments in this paper do not share common elements. There is also a concern about wealth effects (how money earned in one experiment may affect behavior in another). That is also not warranted for this study because money earned in the lottery does not carry over into the auction.

\section{First Price Auction}

In this portion of the experiment the subjects participate in 30 rounds of first price auctions. Each auction lasts 30 seconds, and there are 30 seconds between each auction. The subjects were randomly placed into groups of four. The subjects do not know who the other members of their group are, but they do know that the group consists of the same four members for all 30 rounds.

In each round the subjects draw a number from the uniform distribution $[0,100]$. This number is their value for the hypothetical object being auctioned off. The subjects are informed that their value along with all members' values are drawn from a uniform distribution. The subjects are told in the experiment instruction that it is highly likely that all the members in your group all have different values.

To earn money in this portion of the experiment, a subject must win the auction. The subject who wins the auction receives the difference between his value and the amount he bid for the item. The winner of the auction is revealed at the end of each of the 30 auctions.

\footnotetext{
${ }^{2}$ For a detailed account of this debate see Kagel (1995).
} 


\section{Holt-Laury Lottery}

In the Holt-Laury lottery institution, a subject is given a menu of lottery pairs (Table 1). The subject is to choose either Option A or Option B for each pair of lotteries. The fourth column in Table 1 shows the expected payoff difference of choosing Option A over Option B. ${ }^{3}$ A risk neutral subject will choose Option A until decision five where the expected payoff of selecting Option $A$ becomes negative, and from this point on would only select Option B. A risk loving subject would switch earlier, and a risk averse subject would delay switching until sometime after decision 5 .

Prasad and Salmon computerizes the Holt-Laury device using z-Tree (Fischbacher(1999)). With this protocol subjects saw each choice individually in a sequential order. The subjects, under this protocol, were not allowed to change their decisions once they had been made. Salmon and Prasad claim that this is not a problem for their purposes as it allows for some gauge of the subjects' sophistication. They later use this gauge to analyze behavior in another situation. The claim is that, with their method, it is not as transparent to a subject that he should only have one switching point. The argument is that sophisticated subjects will be able to pick up the underlying incentives of the lottery and only make one switch. Subjects who make many switches may not be paying close attention to the details of the experiment, and knowing this may allow insight into erratic behavior elsewhere. In the event that subjects do have more than one switching point, the decision where they choose Option $B$ and never subsequently choose Option A will be viewed as indicative of their risk preference and in this paper will be referred to as a subject's last switch. After the subjects make all ten decisions, one of the ten chosen lotteries is randomly selected and played for actual earnings.

The lottery and auction experiments were conducted over four sessions and 32 subjects participated. The subjects for the experiment were undergraduates at the Florida State University. The experiment was computer based and conducted with z-Tree software. When the subjects arrived they were assigned to computer terminals. The instructions for the experiment (see Appendix) were read aloud and the subjects had a chance to ask questions. The subjects were paid a $\$ 10.00$ show up fee, and were able to earn money based on their performance in the experiment. The average earnings per subject for the experiment were $\$ 25.00$.

\section{THEORY AND HYPOTHESES}

\section{Deriving Risk Parameters Using a First Price Auction}

By assuming that bidders in an independent private values, first-price, sealed bid auction are risk neutral and that their values $(v)$ are randomly drawn from the uniform distribution $[\underline{v}, \bar{v}]$, Vickrey (1961) showed that the optimal bid function $b_{i}\left(v_{i}\right)$ for a risk neutral bidder in an auction with $n$ bidders is:

$b_{i}\left(v_{i}\right)=\underline{v}+\frac{n-1}{n}\left(v_{i}-\underline{v}\right)$

\section{Equation 1}

This can be estimated as:

$b_{i}\left(v_{i}\right)=\alpha_{i}+\beta v_{i}+\varepsilon_{i}$

${ }^{3}$ The fourth column (difference in expected value) is not shown to the subjects. 


\section{Equation 2}

Milgrom and Weber show that individuals who are risk averse will bid above the optimal bid of a risk neutral bidder. The idea is that people participate in an auction to increase their well being, and they do so by gaining some object at a price lower the value they place on that object. So, their surplus is their value minus their bid (if they win). Low bids increase this surplus, but they lower the likelihood of winning. whereas bids closer to the value of the object decrease the surplus but increase the likelihood of winning. A person who is risk averse will bid higher than a risk neutral person because the risk lies in not capturing the surplus. It follows that the most risk averse person will bid closest to their value, and the least risk averse will bid well below their value. Thus, the estimate of $\beta$ in Equation 2 will be correlated with risk aversion (subjects who are more risk averse will have higher $\beta s$. This gives me a non-parametric measure of risk aversion. Cox Roberson and Smith, and Cox, Smith and Walker construct a parametric measure for risk aversion. They observed that subjects do, in fact, typically bid above $b_{i}$. They subsequently developed what is known as the constant relative risk aversion model (CRRAM) for first price, private value, single unit auctions. The CRRAM assumes that bidders have heterogeneous risk preferences and that all bidders are aware of this. They model this set of beliefs with equation 4 which is similar to equation 1 with a slight modification to include a risk parameter $r_{i}$. We can see that a more risk averse person ( $r$ closer to 0 ) will bid higher than someone who is less risk averse. Cox, Roberson and Smith show the best response to this belief is to respond with the same bid function so long as $b_{i}<\bar{b}$. Beyond this point they cannot solve for a closed form linear solution. To see why, we can consider a simple example. Assume you are a bidder in a two bidder auction, you are risk averse (with $r=0.5$ ), and assume that you believe your rival to be risk neutral ( $r=1)$. If you value the object such that $v=100($ let $\bar{v}=100$, and $\underline{v}=0)$, and bid according to equation 4 , you would bid 66.67. However, this would not be a best response. You know that the most your risk neutral rival would bid is 50. If you believed that your rival was slightly risk averse ( $r=0.8$ ), then the most he would bid is 55.56. In either of these cases, you would want to bid less than 66.67. So, you do not best respond to them by choosing $b_{i}$ where $b_{i}>\bar{b}$. In order to apply this to experiment data Cox, Smith and Walker introduce a method, followed by Isaac and James, to censor their data by eliminating observations where the induced value is above $\left(\frac{n-1}{n} \bar{v}\right)$. This forces $b_{i}<\bar{b}$. The optimal bid function with the CRRAM assumptions in equation 4 also allows for the linear estimation shown in equation 2.

$\bar{b}=\underline{v}+\frac{n-1}{n}(\bar{v}-\underline{v})$

\section{Equation 3}

$b_{i}\left(v_{i}\right)=\underline{v}+\frac{n-1}{n-1+r_{i}}\left(v_{i}-\underline{v}\right)$

\section{Equation 4}

If bidders bid according to the Nash equilibrium, then $\alpha=0$ and we combine equations 4 and 2, we find $\beta$ :

$$
\frac{\underline{v}+\frac{n-1}{n-1+r_{i}}\left(v_{i}-\underline{v}\right)}{v_{i}}=\beta
$$




\section{Equation 5}

Using $\underline{v}=0$, as I will for the experiment, equation 5 allows us to solve for $r_{i}$.

$$
r_{i}=\frac{\left(1-\beta_{i}\right)(n-1)}{\beta_{i}}
$$

\section{Equation 6}

\section{Deriving Risk Parameters Using the H-L Mechanism}

I will use two measures of risk aversion. As noted in Section 2.2, where a subject makes his last switch among the ten decisions in Table 1 is indicative of his risk preference. Subjects who have a high last switch are more risk averse than subjects who have a low last switch. I will use this method because it does not require any underlying assumptions to be made about the subjects' utility function. As a secondary measure, I will derive a range of risk parameters for individual subjects using the CRRA model. This will allow for direct comparison of the CRRAM result in the auction. If we assume that subjects possess constant relative risk aversion utility, their preferences can be represented by the following functional form ${ }^{4}$ :

$U(x)=x^{r}$

\section{Equation 7}

The switching point in the Holt-Laury mechanism allows derivation of the bounds in which a subject's risk parameter must be located. Assume that a subject facing Decision 6 in Table 1 chooses Option B for the first time and continues to choose Option B thereafter. This means that for Decision 5 he views:

$$
E U(A)=0.5(\$ 2.00)^{r}+0.5(\$ 1.60)^{r}>0.5(\$ 3.85)^{r}+0.5(\$ 0.10)^{r}=E U(B)
$$

\section{Equation 8}

and for Decision 6 he views:

$$
E U(B)=0.6(\$ 3.85)^{r}+0.4(\$ 0.10)^{r}>0.6(\$ 2.00)^{r}+0.4(\$ 1.60)^{r}=E U(A)
$$

\section{Equation 9}

Solving equation 8 and 9 shows that a subject who has the utility function in equation 7 has a risk parameter that falls in the range $0.59<r<0.85$. Table 2 lists the risk parameters for possible switches.

${ }^{4}$ Holt and Laury used the utility function $U(x)=\frac{x^{1-r}}{1-r}$. Their bounds will look different but have similar properties. This was done to allow direct comparison to Cox, Smith and Walker (1988) and Isaac and James (2000). 
Table 1: Lottery choices and expected payoff difference of choosing Lottery A over Lottery B

\begin{tabular}{cccc}
\hline \hline Decision & Option A & Option B & Expected Payoff Difference \\
\hline \hline 1 & $1 / 10$ of $\$ 2.00,9 / 10$ of $\$ 1.60$ & $1 / 10$ of $\$ 3.85,9 / 10$ of $\$ 0.10$ & $\$ 1.17$ \\
\hline 2 & $2 / 10$ of $\$ 2.00,8 / 10$ of $\$ 1.60$ & $2 / 10$ of $\$ 3.85,8 / 10$ of $\$ 0.10$ & $\$ 0.83$ \\
\hline 3 & $3 / 10$ of $\$ 2.00,7 / 10$ of $\$ 1.60$ & $3 / 10$ of $\$ 3.85,7 / 10$ of $\$ 0.10$ & $\$ 0.50$ \\
\hline 4 & $4 / 10$ of $\$ 2.00,6 / 10$ of $\$ 1.60$ & $4 / 10$ of $\$ 3.85,6 / 10$ of $\$ 0.10$ & $-\$ 0.16$ \\
\hline 5 & $5 / 10$ of $\$ 2.00,5 / 10$ of $\$ 1.60$ & $5 / 10$ of $\$ 3.85,5 / 10$ of $\$ 0.10$ & $-\$ 0.51$ \\
\hline 6 & $6 / 10$ of $\$ 2.00,4 / 10$ of $\$ 1.60$ & $6 / 10$ of $\$ 3.85,4 / 10$ of $\$ 0.10$ & $-\$ 0.85$ \\
\hline 7 & $7 / 10$ of $\$ 2.00,3 / 10$ of $\$ 1.60$ & $7 / 10$ of $\$ 3.85,3 / 10$ of $\$ 0.10$ & $-\$ 1.18$ \\
\hline 8 & $8 / 10$ of $\$ 2.00,2 / 10$ of $\$ 1.60$ & $8 / 10$ of $\$ 3.85,2 / 10$ of $\$ 0.10$ & $-\$ 1.52$ \\
\hline 9 & $9 / 10$ of $\$ 2.00,1 / 10$ of $\$ 1.60$ & $9 / 10$ of $\$ 3.85,1 / 10$ of $\$ 0.10$ & $-\$ 1.85$ \\
\hline 10 & $10 / 10$ of $\$ 2.00,0 / 10$ of $\$ 1.60$ & $10 / 10$ of $\$ 3.85,0 / 10$ of $\$ 0.10$ & \\
\hline
\end{tabular}

Table 2: Risk parameter derived from last switch

\begin{tabular}{ccc}
\hline Last S witch & $\begin{array}{c}\text { Range Of } \\
\text { Relative Risk Aversion } \\
\text { for } \mathbf{U}(\mathbf{x})=\mathbf{x}^{r}\end{array}$ & $\begin{array}{c}\text { Risk Preference } \\
\text { Classification }\end{array}$ \\
\hline $1-2$ & $\begin{array}{c}r>1.95 \\
\text { highly risk loving }\end{array}$ \\
\hline 3 & $1.49<r<1.95$ & very risk loving \\
\hline 4 & $1.15<r<1.49$ & risk loving \\
\hline 5 & $0.85<r<1.15$ & risk neutral \\
\hline 6 & $0.59<r<0.85$ & slightly risk averse \\
\hline 7 & $0.32<r<0.59$ & risk averse \\
\hline 8 & $0.03<r<0.32$ & very risk averse \\
\hline 9 & $-0.37<r<0.03$ & highly risk averse \\
\hline 10 & $r<-0.37$ & stay in bed \\
\hline
\end{tabular}

\section{HYPOTHESES}

Hypothesis 1: The aggregated mean CRRAM risk parameter from the first price auction and the mean last switch in the Holt Laury lottery risk parameter are consistent with past subject pools, and the mean CRRAM risk parameter in the auction falls within the CRRAM range of the risk parameters derived from the lottery.

Recall that Harrison showed that his subject pool's risk estimate was different than the risk estimate obtained by Cox, Smith and Walker. Isaac and James had the same subject pool participate in two different institutions and found that the risk parameter estimates were not consistent

In my experiment, I have observations for the same subject pool in different institutions. I can also compare my results in the auction to the past results of Cox, Smith and Walker, and Isaac and James, and my results in the lottery to those of Holt and Laury and Prasad and Salmon to see how my subjects' behavior in each institution compares with other subjects in similar institutions. By validating that my subjects behave similarly to past subjects, I can be confident that any further findings in this study are not special to my subject pool. If my subjects as a group behave consistently across institutions, it becomes worthwhile to study them at the individual level. If there was a preference reversal in the mean, the possibility for consistency at the individual level would be eliminated. 
Hypothesis 2: The ranking of subjects by their risk tolerance (both $\beta$ and $r$ in the auction and last switch and $r$ in the lottery) is consistent across the auction and the lottery.

If subjects are found to have different risk parameter values in different institutions, it could be the case that there is simply a shift and the subjects would maintain their relative ranking i.e. subject $A$ would be more risk averse than subject $B$ in both institutions. If subjects at least maintain their ranking, we can be confident that the modeling techniques are capturing something salient about the subjects. It could be the case that for some reason context makes the subjects more risk averse in one institution than the other. This would still be troubling when trying to speak generally about behavior, but it would be less troubling than subjects' ranks varying wildly between institutions. If subjects' ranks are not consistent we would have to figure out what kind of semantic game we are playing with the word risk.

Hypothesis 3: Individual subjects exhibit the same level of risk tolerance in different institutions. Subjects $\beta$ should be correlated with last switch and under the CRRAM assumptions, a subject's risk parameter in the auction should fall in the corresponding range of risk parameters derived in the lottery.

The point of developing economic models is to be able to predict how people will behave. If an individual has certain tendencies when making a decision that entails uncertainty, it should be the case that these tendencies are similar regardless of the institution. We can think of it this way, suppose a person does not like peanuts. I can then predict that he will never willingly eat peanuts, and I will feel very confident in my prediction. But, what if this person only dislikes peanuts sometimes? My attempts at predicting his behavior becomes more taxing. I have to start worrying about context, maybe he likes peanuts when he is at a baseball game, but he does not like peanuts when he is watching baseball at home. This is a more difficult situation to model. Imagine I had to forecast demand for peanuts. If everyone had consistent peanut preferences, my job is not that hard. But if demand for peanuts changes with context, forecasting is much harder. Now I have to approximate baseball attendance. I can still do a forecast, but I will be much less confident in my prediction. If we think about risk aversion, we can view it as someone not liking risk. As an economist, I will feel much more comfortable about my predictions if people do not like risk by the same amount whether or not they are at a baseball game.

\section{RESULTS}

Result 1: Subjects (as a group) in the first price auction behave consistently with the subjects in Cox, Smith and Walker. Subjects in the Holt-Laury lottery behave consistently with the subjects in Holt and Laury and Prasad and Salmon. In the current study, the mean risk parameter in the auction, calculated with the CRRA model, falls within the range that these same subjects exhibited in the lottery.

In this section I will show that my subjects behaved as other subjects did in the same institution. By replicating the past experiments, we can diminish any critique that further results are determined by a subject pool effect. Table 3 shows the last switch observed for subjects using the H-L mechanism in my experiment and two past experiments. Holt and Laury report the mean last switch in their experiment is 6.2 which implies risk aversion and a CRRAM risk parameter in the range $0.59<r<0.85$. Prasad and Salmon report that the mean last switch in their experiment is 7.06 which implies a risk parameter in the range $0.32<r<0.59$. I find that the mean last switch in my experiment is 6.86 , which implies a risk parameter in the range $0.32<r<0.59$. The reported last switches for all three experiments are not statistically different ( $p-$ value $=0.63$ for comparison with P-S, $p-$ value $=0.11$ for comparison with $\mathrm{H}-\mathrm{L}$ ). Subjects in my experiment are behaving consistently with subjects in prior experiments.

Table 4 shows the mean implied risk parameters of subjects participating in a first-price, sealed bid auction. I find a mean estimate of $r=0.37$ which is between the parameters found by Cox, Smith and Walker and Isaac and James. CSW find a mean estimate of $r=0.35$, I-J find a mean estimate of $r=0.50$. All of these estimates 
imply risk aversion. My results are not statistically different than CSW $(p-$ value $=0.6624)$. However, my results are statistically different than I-J $(p-$ value $=0.0162) .{ }^{5}$ The key aspect of risk preference is not changed, just the level. This could easily be due to my subject pool being slightly different than I-J. It should be pointed out that my experiment and CSW had four human subjects bidding against each other, where I-J had one human bid against four risk neutral robots, though Walker, Smith and Cox (1987) found no significant difference in how subjects behave when bidding against robots instead of humans.

Table 5 shows that the implied risk parameter for the group in the auction falls within the range of the implied risk parameter for the group in the lottery. This does not yet prove that subjects at the individual level behave the same way in each institution, but allows for the possibility. There would be no need to run individual subject level tests if the result had been the opposite, and we could be confident that subjects do not behave the same way in different institutions.

Table 3: Mean last switch in lottery with different subject pools

\begin{tabular}{cccc}
\hline Lottery & H - L & P - S & E \\
\hline Last S witch & 6.2 & 7.06 & 6.86 \\
\hline Derived risk parameter & $0.59<r<0.85$ & $0.32<r<0.59$ & $0.32<r<0.59$ \\
\hline
\end{tabular}

Table 4: Mean risk parameter in auctions with different subject pools

\begin{tabular}{cccc}
\hline Auction & CS W & I - J & E \\
\hline Risk Parameter $(r)$ & 0.35 & 0.50 & 0.37 \\
\hline
\end{tabular}

Table 5: Mean risk parameter in auction and lottery with the same subject pool

\begin{tabular}{lcc}
\hline & Auction & Lottery \\
\hline Risk Parameter $(r)$ & 0.37 & $0.32-0.59$ \\
\hline
\end{tabular}

Result 2: The ranking of subjects from most to least risk averse is consistent across institutions.

The first way I have chosen to test cross task consistency is to rank subjects in each institution and examine if these rankings are consistent across institutions. I do not need to assume an underlying model to do this because subjects can be ranked based on their $\beta$ and their last switch. After ranking the subjects from most risk averse (high values of $\beta$ ) to least risk averse (low values of $\beta$ ) a Spearman test was conducted to test rank preservation. I find that there is a positive correlation, $(\rho=0.35)$ but it is not significant at the $10 \%$ level (it is significant at the $11 \%$ level). So we do see a positive correlation in ranks, but the significance is tenuous. This lack of significance could be due to the way subjects' ranks are determined in the auction versus how they are ranked in the lottery. Recall that in the auction, there is an explicit estimate of $\beta$. In the lottery, subjects' ranks are determined by where they switch to Option B. The lottery does not give a point estimate for risk aversion. This could possibly create a problem because tiny differences in the auction could lead to a large difference of where a subject ranks in the auction, but subjects who have last switch 7 cannot be ranked within that bin. It is easier think about this in terms of the CRRAM. With the CRRAM we can derive point estimates in the auction, but only bins over a range of risk parameters in the lottery. For example, subjects 1,2 and 19 in the lottery switch to Option B at

\footnotetext{
${ }^{5} \mathrm{I}-\mathrm{J}$ state that their results are not statistically different from CSW. CSW have a smaller subject pool than I do, and therefore a
} larger confidence interval. I-J's estimate falls within CSW's interval, but not mine. 
decision 7 which places their risk parameter in the range $0.32<r<0.59$. In the auction, the subjects have $r=0.42,0.58$, and 0.36 (respectively). This means that subjects 1,2 , and 19 's estimates from the auction fall within the range found in the lottery. But, when these subjects are ranked, the lottery ranks them all at 11 (since they are tied), while the auction ranks them at 15,19 , and 12 . I have taken subjects' risk parameter estimates from the auction and put them into the same range that the estimates from the lottery fall (Table 6). What I am forcing here is not that ranks across institutions be similar, but that ties in one institution are considered ties in the other institution. Figure 1 shows scatterplot of both the actual rankings and the hypothetical rankings from the auction on the rankings from the lottery. Using these created last switch estimates, I have re-estimated Spearman's $\rho$ and find a much stronger correlation ( $\rho=0.59$ ) with significance at the $5 \%$ level.

Table 6: Subjects' revised auction rankings. This places subjects' auction risk parameters in bins consistent with those derived in the lottery

\begin{tabular}{cccccc}
\hline Subject & r (auction) & r (lottery) & Rank (auction) & Rank (lottery) & Rank (new) \\
\hline 1 & 0.42 & $0.32<r<0.59$ & 15 & 11 & 16 \\
\hline 2 & 0.58 & $0.32<r<0.59$ & 19 & 11 & 16 \\
\hline 19 & 0.36 & $0.32<r<0.59$ & 12 & 11 & 16 \\
\hline
\end{tabular}

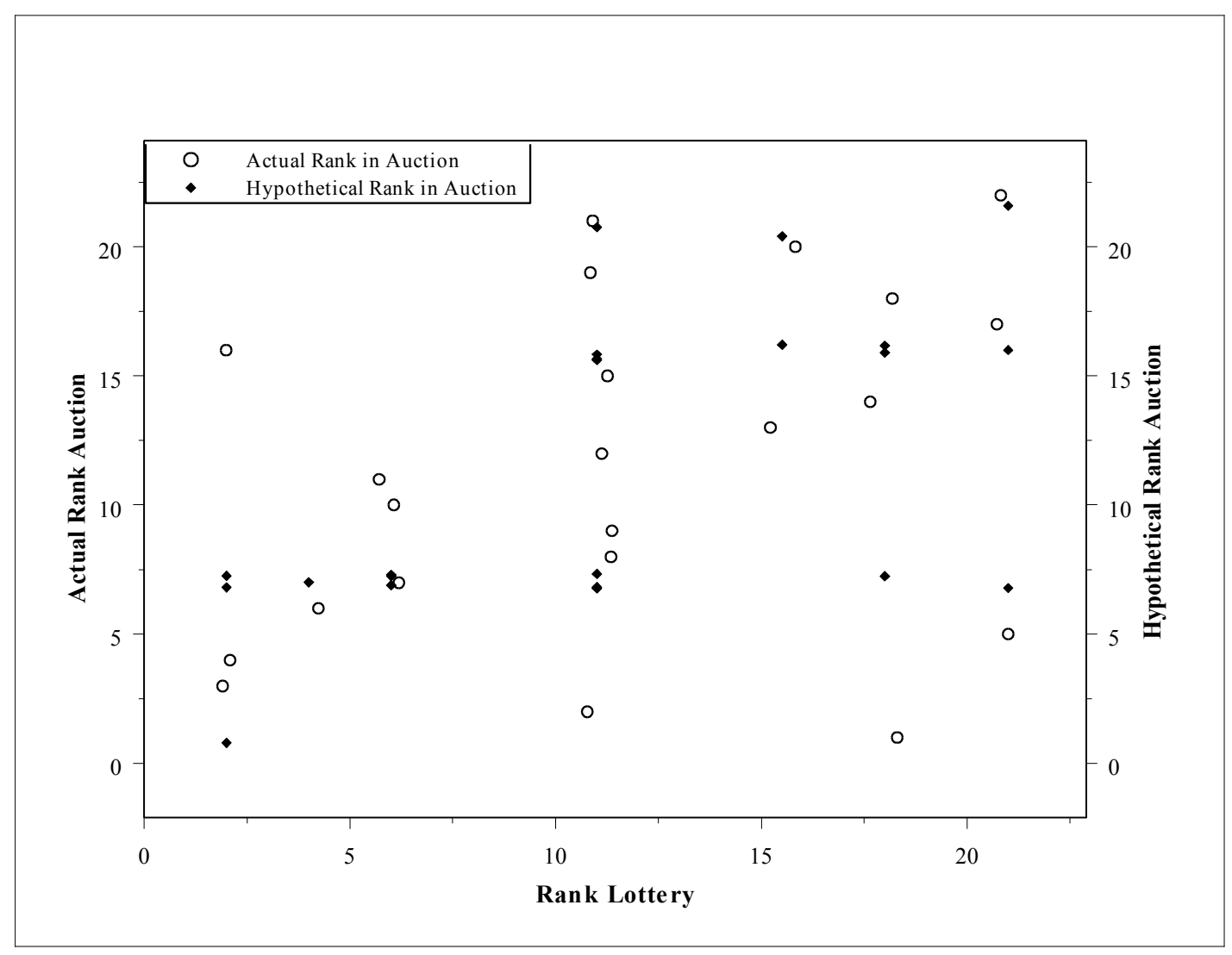

Figure 1: Within subject comparison between institutions (ranks) 
Result 3: Individual subjects behave consistently across different institutions. Subjects' risk aversion measured by both their $\beta$, and their CRRAM parameter $(r)$ in the first price auction is consistent with subjects' risk aversion measured by their last switch in the lottery. Further, the CRRAM parameter from the first price auction is consistent with the CRRAM parameters derived from the lottery.

We saw in Result 1 that my subjects behave as subjects in past experiments behaved. I can now address the more important question of whether individuals behave similarly across institutions. The first test I will use is an Ordered Logit regression. This test is used because the H-L Lottery does not allow for derivation of point estimates for a subject's risk preference. The Ordered Logit allows for using the last switch levels directly as the dependent variable. Table 7 reports the results of an Ordered Logit Regression where I have regressed the last switch subjects made in the H-L Lottery on the coefficient of a subjects value estimated by their linear bid function in the first price auction ( $\beta$ ). Table 7 also reports the results of the same test using the CRRAM derived risk parameter (r) instead of $\beta$. I find that there is significant relationship between the two variables for both $\beta$ and last switch, and $r$ and last switch. In other words, the more risk averse a subject is in the first price auction, the more likely it is that he would be more risk averse (have a high switching point) in the H-L Lottery. Given the intercept ( $\alpha_{1}$ through $\alpha_{6}$ ) and the coefficient, it is possible to construct probabilities of making a specific last switch given some $\beta$. For example, to calculate the probability that an individual with $\beta=0.8$ makes his last switch at decision 7:

$$
\frac{e^{\alpha_{4}-\beta(0.8)}}{1+e^{\alpha_{4}-\beta(0.8)}}=\frac{e^{15.482-16.433(0.8)}}{1+e^{15.482-16.433(0.8)}}=0.912
$$

\section{Equation 10}

Figure 2 shows the estimated probability of a subject having a particular Last Switch given their estimated $\beta$. For example, if a subject on average bids $80 \%$ of his value $(\beta=0.8)$ there is a $91.2 \%$ chance that he made his last switch at decision 7 or lower, and more specifically, there is a $22 \%$ chance that he made his Last Switch exactly decision 7. In the first panel when $\beta=0.6$ we can see that the probability is heavily skewed towards of a subject making their last switch early, while $\beta=0.99$ the probability is heavily skewed towards of a subject making their last switch late. We can see similar results using the risk parameter $r$ in Figure 3. The data is limited to having a Last Switch lower bound of 4 because no subjects were observed to switch earlier than that.

Table 7: Ordered Logit Regression of the subjects' last switch in the lottery on the Beta coefficient in the auction and the CRRAM risk parameter

\begin{tabular}{cccccccc}
\hline & Coef & Std Err & $\mathbf{P}>|\mathbf{z}|$ & & Coef & StdErr & $\mathbf{P}>|\mathbf{z}|$ \\
\hline Beta Auction & 16.433 & 8.224 & 0.046 & Risk Auction & -4.199 & 2.06 & 0.042 \\
\hline$\alpha_{1}$ & 12.523 & 7.158 & 0.080 & $\alpha_{1}$ & -3.7285 & 1.18 & 0.001 \\
\hline$\alpha_{2}$ & 13.493 & 7.220 & 0.062 & $\alpha_{2}$ & -2.738 & 1.028 & 0.008 \\
\hline$\alpha_{3}$ & 13.956 & 7.248 & 0.054 & $\alpha_{3}$ & -2.27 & 0.983 & 0.021 \\
\hline$\alpha_{4}$ & 15.482 & 7.393 & 0.037 & $\alpha_{4}$ & -0.742 & 0.866 & 0.391 \\
\hline$\alpha_{5}$ & 16.322 & 7.460 & 0.029 & $\alpha_{5}$ & 0.0948 & 0.875 & 0.914 \\
\hline$\alpha_{6}$ & 16.700 & 7.489 & 0.026 & $\alpha_{6}$ & 0.4692 & 0.905 & 0.605 \\
\hline
\end{tabular}




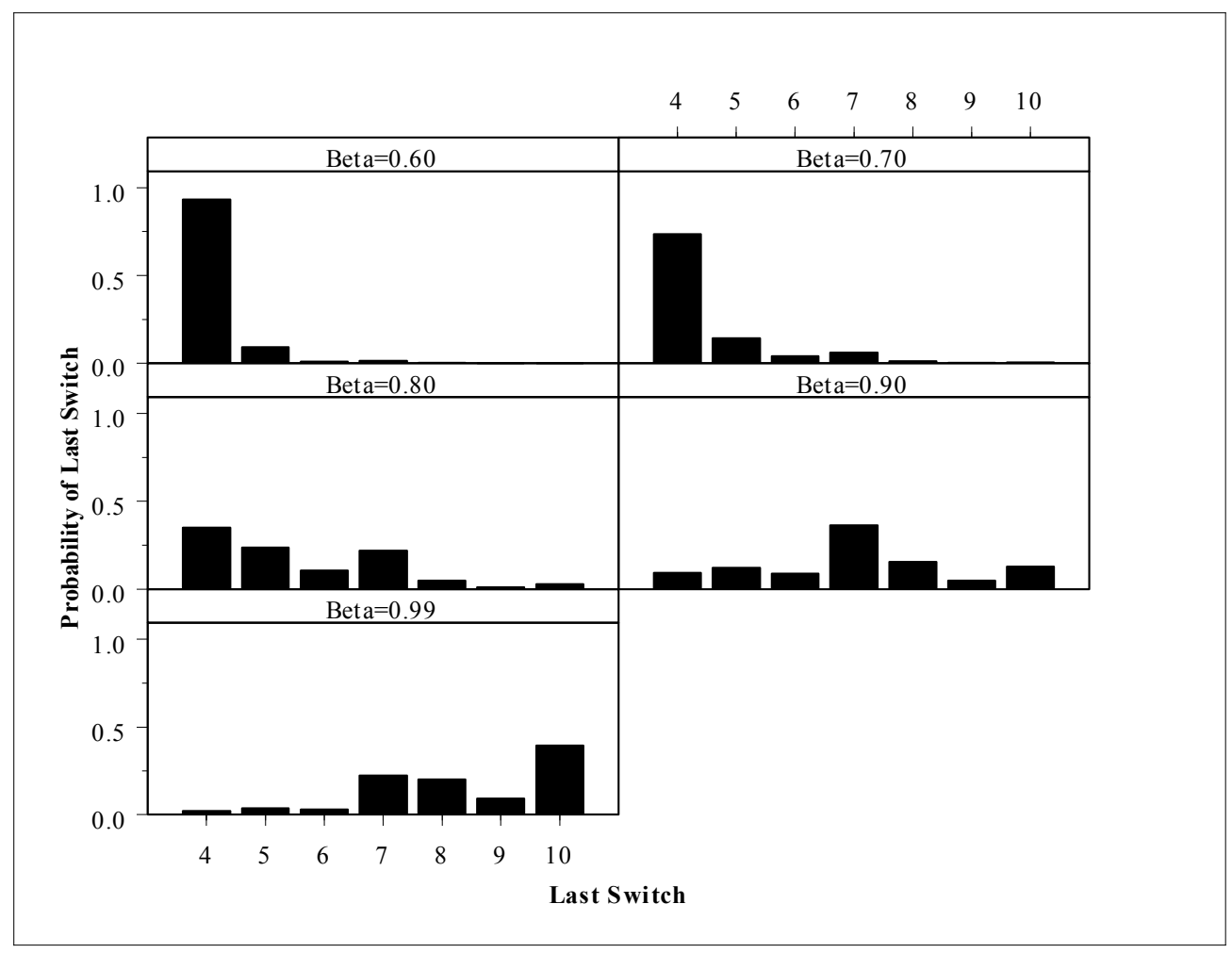

Figure 2: Probability of specific last switch for a given Beta 


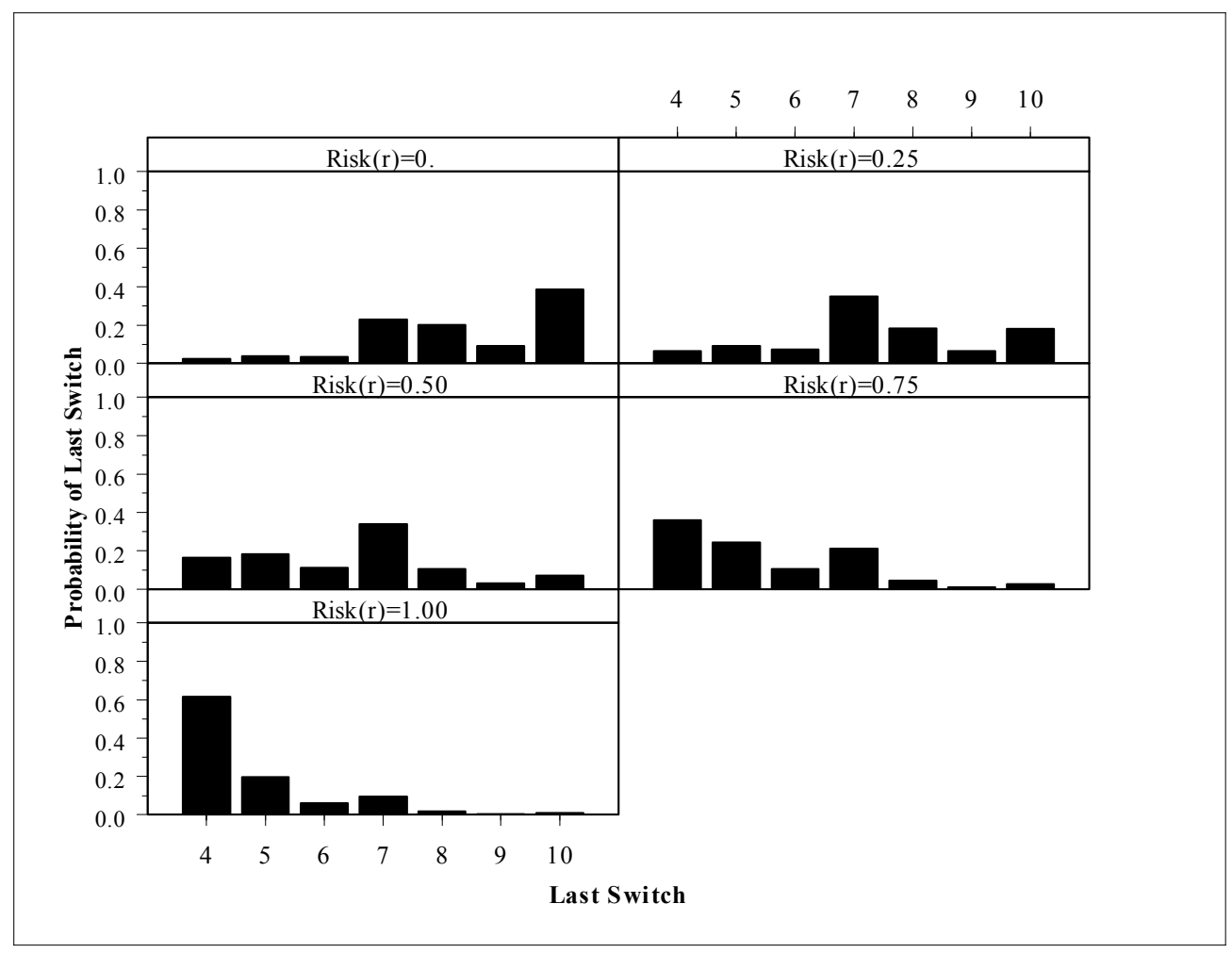

Figure 3: Probability of specific last switch for a given risk parameter

The results of the Ordered Logit are consistent with an individual behaving similarly in both institutions. However, when we are examining the CRRAM model, the Ordered Logit is only testing that the auction derived parameter is consistent with the dependent variable last switch. So, a higher risk parameter was consistent with a lower last switch but it did not test if the numerical value of the risk parameter fell within the range of numerical values that can be backed out of the lottery. We can better evaluate the CRRAM results by looking explicitly at each subject's derived parameter in both institutions. Table 8 shows subjects derived risk parameters in both the lottery and the auction. There are 7 out of 22 subjects ( $32 \%$ ) whose risk parameter, derived from the auction, falls within the range of the risk parameter derived in the lottery. Of the remaining 15 subjects, 10 are more risk averse in the first price auction than in the lottery institution. This means that 17 out of the $22(77 \%)$ are at least as risk averse in the lottery institution as they are in the first price auction. It is noteworthy that three of the subjects who were more risk averse in the lottery than the auction did not switch to Option $B$ in the lottery until the high payoff was assured. These three subjects were quite risk averse in the auction ( $r=0.11,0.18,0.44)$. This is of interest because if a subject bids very close to their value (extremely risk averse) the lowest $r$ that can be estimated for them is 0 . Whereas subjects who do not switch to Option $B$ in the lottery until it a sure thing will have an estimated risk parameter of $r<-0.37$. So it would be impossible for a subject to be as risk averse in the auction as someone whose made their last switch at decision 10. If we look at Figure 4 (a plot of risk parameter ranges from the lottery plotted on the risk parameter values derived from the auction) we can see that there appears to be a strong positive correlation between the range from the lottery and the point estimates from the auction. 
Table 8: Subject CRRAM risk parameter estimates in each institution

\begin{tabular}{ccccccccc}
\hline Subject & RP (HL) & RP (FPA) & HL - FPA & S ubject & RP (HL) & RP (FPA) & HL - FPA \\
\hline 1 & $0.32<r<0.59$ & 0.42 & 0 & 16 & $0.32<r<0.59$ & 0.29 & 0.03 \\
\hline 2 & $0.32<r<0.59$ & 0.58 & 0 & 19 & $0.32<r<0.59$ & 0.36 & 0 \\
\hline 3 & $0.32<r<0.59$ & 0.09 & 0.23 & 20 & $r<-0.37$ & 0.18 & -0.55 \\
\hline 4 & $1.15<r<1.49$ & 0.45 & 0.70 & 21 & $0.85<r<1.15$ & 0.06 & 0.79 \\
\hline 5 & $0.32<r<0.59$ & 0.30 & .02 & 22 & $0.85<r<1.15$ & 0.55 & 0.30 \\
\hline 6 & $0.85<r<1.15$ & 0.40 & .45 & 24 & $-0.37<r<0.03$ & 0.22 & -0.19 \\
\hline 9 & $0.32<r<0.59$ & 0.67 & -0.08 & 26 & $0.03<r<0.33$ & 0.26 & 0 \\
\hline 10 & $0.32<r<0.59$ & 0.19 & 0.13 & 28 & $0.03<r<0.33$ & 0.30 & 0 \\
\hline 12 & $0.59<r<0.85$ & 0.39 & 0.20 & 29 & $0.03<r<0.33$ & 0.30 & 0 \\
\hline 13 & $r<-0.37$ & 0.11 & -0.48 & 30 & $1.15<r<1.49$ & 1.09 & 0.06 \\
\hline 15 & $r<-0.37$ & 0.44 & -0.81 & 31 & $0.59<r<0.85$ & 0.59 & 0 \\
\hline
\end{tabular}

Correlation, however, is not enough to say that subjects behave the same way in each institution. It could be the case that subject are always more risk averse in one institution than the other. We have seen in Result 2 that subjects are ranked similarly in both institutions, but that does not guarantee that the risk parameter for the subject is the same in both institutions. To examine this, I first have to see if there is, in fact, significant correlation. To do this,

I have used subjects' $r$ estimates from the auction to see where they would have last switched in the lottery from Option A to Option B (i.e. assume the risk parameter from auction is true and then derive how a subject with that risk parameter would act in the lottery). I call this the implicit last switch. We can see the result of this in Table 9 and Figure 5 shows a scatterplot the actual last switch on the implicit last switch. With this sorting, I can now check for correlation between the actual last Switch and the implicit last switch. I find that these are positively correlated at the 5\% level ( Pearson $r=0.56$ ). With the assurance of this correlation, I can now examine the relationship between the two institutions by regressing the actual last switch on the implicit last switch. Table 10 reports the results of this test. The coefficient of the implicit last switch is positive and significant at the $1 \%$ level. The result of the coefficient being equal to 1.16 is somewhat counter-intuitive given that the constant term is not significantly different than zero, since this implies that subjects are slightly more risk averse in the lottery than the auction. This is counter-intuitive because we have seen that 10 of the $15(67 \%)$ subjects whose derived risk parameter from the auction was outside of the bounds of that derived by the lottery were more risk averse in the auction than in the lottery. The constant term is not reported as being significantly different than zero, but it is reported as negative. I have suppressed the constant term and re-run the regression and find that forcing the constant term to zero returns the more intuitive result of the coefficient on the implicit last switch being less than 1 (the coefficient is equal to 0.93). The most important result is that the coefficient is close to one. This means that not only is the behavior correlated, but subjects are behaving the same way in each institution. 
Table 9: Subjects' last switch in lottery and implicit last switch derived from the auction

\begin{tabular}{|c|c|c|c|c|c|}
\hline Subject & LS (actual) & LS (implicit) & Subject & LS (actual) & LS (implicit) \\
\hline 1 & 7 & 7 & 16 & 7 & 8 \\
\hline 2 & 7 & 7 & 19 & 7 & 7 \\
\hline 3 & 7 & 8 & 20 & 10 & 8 \\
\hline 4 & 4 & 7 & 21 & 5 & 8 \\
\hline 5 & 7 & 8 & 22 & 5 & 7 \\
\hline 6 & 5 & 7 & 24 & 9 & 8 \\
\hline 9 & 7 & 6 & 26 & 8 & 8 \\
\hline 10 & 4 & 8 & 28 & 8 & 8 \\
\hline 12 & 6 & 7 & 29 & 8 & 8 \\
\hline 13 & 10 & 8 & 30 & 4 & 5 \\
\hline 15 & 10 & 9 & 31 & 6 & 6 \\
\hline
\end{tabular}

Table 10: Results of regressing the actual last switch on the implicit last switch, and results of same regression with suppressed constant

\begin{tabular}{ccccc}
\hline & Coef. & S td. Err. & $\mathbf{t}$ & $\mathbf{P}>|\mathbf{t}|$ \\
\hline Last S witch (implicit) & 1.16 & 0.38 & 3.04 & 0.006 \\
\hline Constant & -1.79 & 2.86 & -0.63 & 0.539 \\
\hline
\end{tabular}

\begin{tabular}{llll} 
Coef. Std.Err. & $\mathbf{t}$ & $\mathbf{P}>|\mathbf{t}|$ \\
\hline
\end{tabular}

\begin{tabular}{lllll}
\hline Last S witch (implicit) & 0.93 & 0.045 & 20.69 & 0.000 \\
\hline
\end{tabular}

Constant 


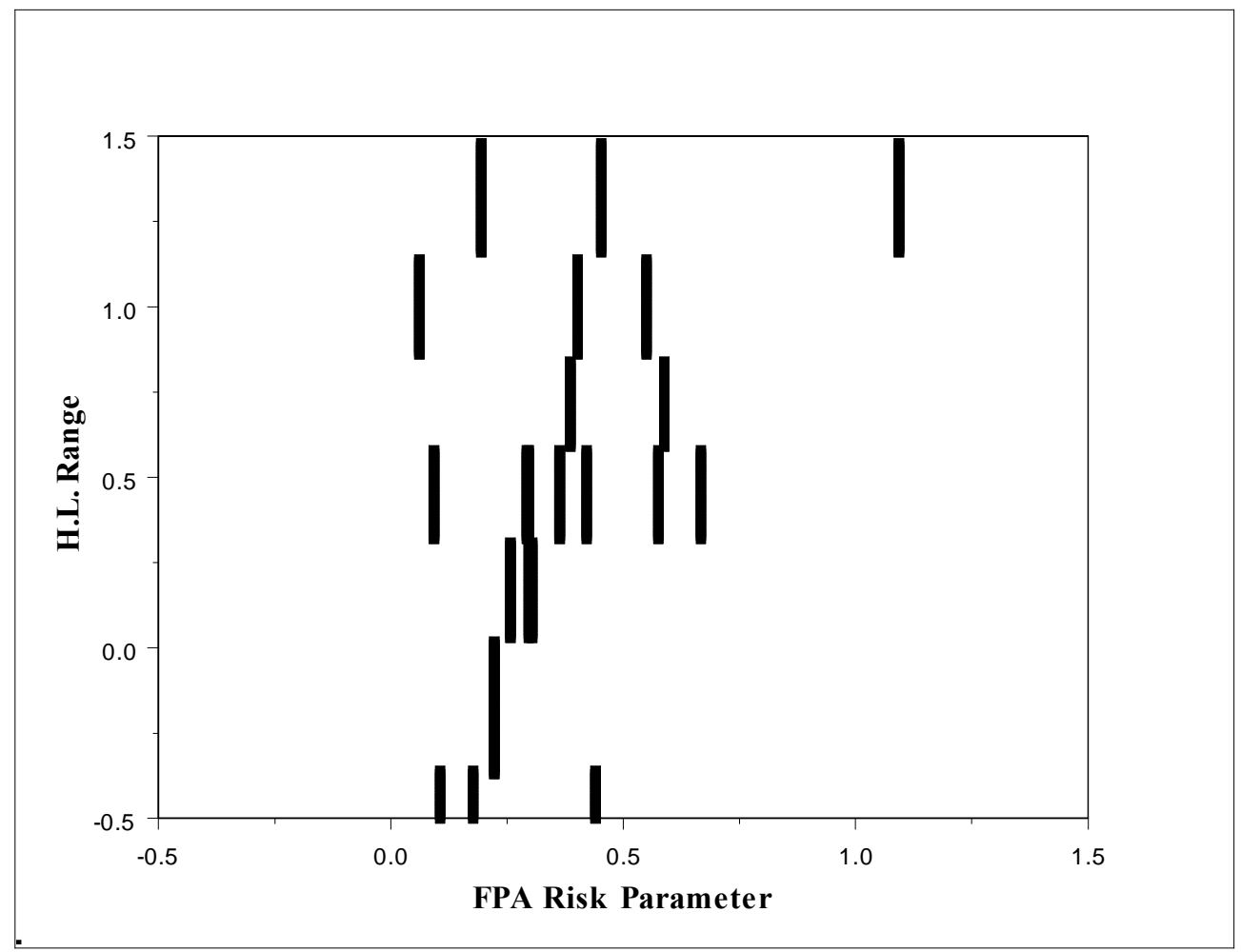

Figure 4: Scatterplot of derived CRRAM risk parameter from the lottery and the auction 


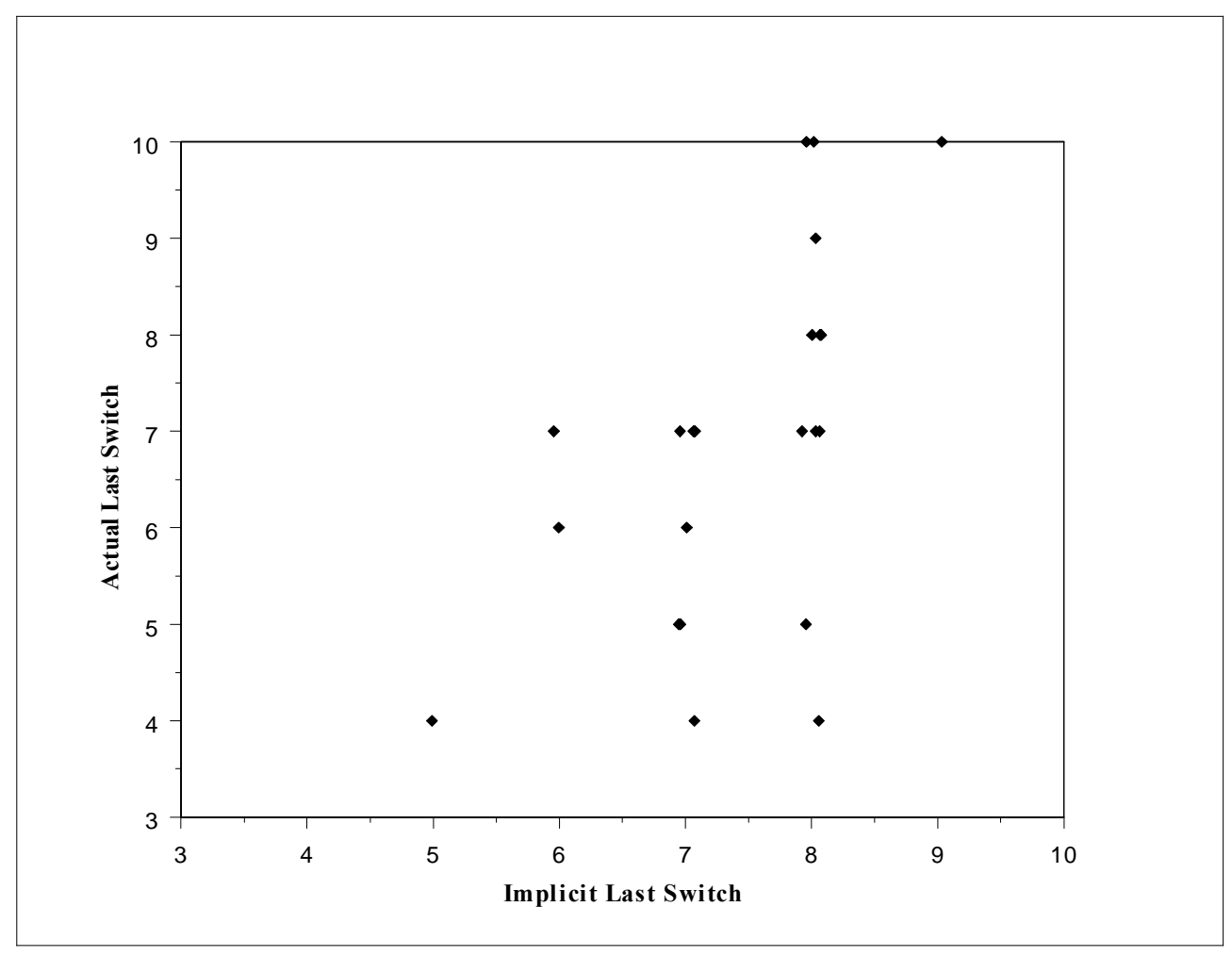

Figure 5: Scatterplot of the actual last switch made by subjects on implicit last switch derived by subject behavior in the auction

\section{CONCLUSION}

When developing economic models, certain assumptions are made. One assumption commonly made is that individuals will respond to uncertainty in a consistent way. Individuals may be different, but there is internal consistency to their behavior (Joe is not the same as John, but Joe behaves the same way in different institutions). Recent laboratory experiments have questioned the validity of this assumption. I add to this literature by having the same subjects participate in two different institutions (the Holt and Laury lottery and a first price auction) that allow for inferences to be made about their risk tolerance. A nice feature of the two institutions I have used is that they do not rely on specific utility functions for analysis of risk preferences; though it is possible to back out specific parameters if they are desired.

Subjects in my experiment behave consistently with subjects in past experiments given the same institution. So, there is nothing special about my subject pool in this regard. Further the behavior of the group across institutions is similar. The most important result is that individuals behave consistently across these two institutions. Using nonparametric measures, I find that subjects who are more risk averse in one institution are likely to be more risk averse in the other institution. Beyond that, I find that the parametric estimates derived by using the CRRA model hold up quite well across institutions.

These results do not allow me to generalize that individuals will always behave with consistent risk preferences in all institutions. There is still the question of what was happening in the BDM mechanism in past research. Isaac and James (2000) is titled Just Who Are You Calling Risk Averse?, and there is a question in the literature of whether subjects in first price auctions merely bid 'as if' risk averse. My results support the argument that subjects bid 'as if' risk averse because they are, in fact, risk averse. 


\section{ACKNOWLEDGEMENTS}

I would like to thank Mark Isaac, Tim Salmon, and the participants of The Florida State University Experimental Economics Readings Group for helpful comments. Funding for the experiment was provided by the John and Hallie Quinn fellowship. All remaining errors are my own.

\section{AUTHOR INFORMATION}

Dr. Russell P. Engel is an Assistant Professor of Business Economics at Sacred Heart University in Fairfield Connecticut. His research interests are in Applied Microeconomics, Experimental Economics and Game Theory. E-mail: engelr@sacredheart.edu

\section{REFERENCES}

1. Becker, Gordon M., Morris H. Degroot, and Jacob Marschak. (1964). Measuring Utility by a SingleResponse Sequential Method, Behavioral Science 9, 226-232.

2. Cox, James C., Bruce Roberson, and Vernon L. Smith. (1982). Theory and Behavior of Single-Object Auctions, In V. L. Smith (ed.), Research in Experimental Economics, Vol. 2. Greenwich, Conn.: JAIPress, Inc.

3. Cox, James C., Vernon L. Smith, and James M. Walker. (1988). Theory and Individual Behavior of FirstPrice Auctions, Journal of Risk and Uncertainty 1, 61-99.

4. Goeree, Jacob K., Charles A. Holt, and Thomas Palfrey (1999) Quantal Response Equilibrium and Overbidding in Private-Value Auctions, Discussion Paper, California Institute of Technology.

5. Harrison, Glenn W. (1990). Risk Attitudes in First-Price Auction Experiments: A Bayesian Analysis, Review of Economics and Statistics 72, 541-546.

6. Holt, C. and S. Laury (2002). Risk Aversion and Incentive Effects, American Economic Review 92 (5), 1644-1655.

7. Isaac, R. M. and D. James (2000). Just Who Are You Calling Risk Averse?, Journal of Risk and Uncertainty 20 (2), 177-187.

8. Kagel, John H.; Harstad, Ronald M. and Levin, Dan. Information Impact and Allocation Rules in Auctions with Affiliated Private Values: A Laboratory Study. Econometrica, November 1987, 55(6), pp. 1275-304.

9. Kagel, John, Auctions: A Survey of Experimental Research, in J.H. Kagel and A.E. Roth (eds.), The Handbook of Experimental Economics, Princeton: Princeton University Press (1995).

10. Milgrom, Paul and Robert Weber, A Theory of Auctions and Competitive Bidding, Econometrica (1982), 50: pp. 1089-1122.

11. Prasad, K and T. C. Salmon (2007). Self Selection and Market Power in Risk Sharing Contracts, Working Paper Florida State University.

12. Smith, Vernon L. and James M. Walker (1993) Rewards, Experience, and Decision Costs in First-Price Auctions, Economic Inquiry, 31, 237-245.

13. Walker, James M., Vernon L. Smith and James C. Cox. (1987). Bidding Behavior in First Price Sealed Bid Auctions: Use of Computerized Nash Competitors, Economics Letters 23, 239-244. 


\section{APPENDIX}

\section{Experimental Instructions}

\section{Experiment Instructions I}

In each round of this series you will be asked to make a choice between two lotteries that will be labeled A and B. There will be a total of 10 rounds and after you have made your choice for all 10 rounds, one of those rounds will be randomly chosen to be played. Lottery A will always give you the chance of winning a prize of $\$ 2.00$ or $\$ 1.60$, while lottery $\mathrm{B}$ will give you the chance of winning $\$ 3.85$ or $\$ 0.10$. Each decision round will involve changing the probabilities of your winning the prizes. For example in round 1, your decision will be represented on the screen in front of you (activate program now):

Your decision is between these two lotteries:

Lottery A: A random number will be drawn between 1 and 100. You will win

$\$ 1.60$ if the number is between $1-90$ (90\% chance)

$\$ 2.00$ if the number is between 91 and 100 (10\% chance)

Lottery B: A random number will be drawn between 1 and 100. You will win

$\$ 0.10$ if the number is between 1 and 90 (90\% chance)

$\$ 3.85$ if the number is between 91 and 100 (10\% chance)

If you were to choose lottery B and this turns out to be the round actually played, then the computer will generate a random integer between 1 and 100 with all numbers being equally likely. If the number drawn is between 1 and 90 , then you would win $\$ 0.10$ while if the number is between 91 and 100 , then you would win $\$ 3.85$. Had you chosen lottery A then if the number drawn were between 1 and 90 you would win $\$ 1.60$ while a number between 91 and 100 would earn you $\$ 2.00$.

All of the other 9 choices will be represented in a similar manner. Each will give you the probability of winning each prize as well as translate that probability into the numerical range the random number has to be in for you to win that prize.

At the end of the 10 choice rounds, you will be asked to press a button that will allow the computer to determine your payment. When you do so, the computer will randomly pick one of the 10 rounds to base your payment on, remind you of the choice you made in that round and draw the random number between 1 and 100 to determine your earnings.

Are there any questions before you begin making your decisions?

We ask that you follow the rules of the experiment and in particular we again ask that you do not talk or look at the screens of other participants during the experiment. Anyone who violates the rules may be asked to leave the experiment with only the $\$ 10.00$ show-up fee.

You will now start the sequence of 10 choices. You will be able to go through the choices at your own pace, but we will not be able to continue the experiment until everyone has completed this series.

So now please look at your computer screen, you can determine your choice by clicking on the circle beside it. Now you may begin making your choices. Please do not talk to anyone while you are doing this; raise your hand if you have a question.

\section{Experiment Instructions II}

In this part of the experiment, you will be a bidder in an auction. You are one member in a group of four. On your handout you will see something called your value this is how much the item that you are bidding on is 
worth to you, the other three players have their own value. Your value will be a random integer between 0 and 100 , with all numbers being equally likely. Your value is randomly selected for each member of your group. It is highly likely that all the members in your group all have different values.

You have to decide how much you are willing to bid for the object, given your value. You will be bidding against 3 other people in this room. The person who submits the highest bid (on the handout you will see a box marked your bid) will be the winner of the auction. The winner of the auction will earn their value minus their bid. For example, assume your value is 65 , and you bid 55 . If 55 is the highest bid, your profit would be $65-55=10$. If you do not win, you earn zero.

You will start this portion of the experiment with 25 ECUs. If you bid above your value (i.e. your bid is greater than your value), and you win the item, you will make losses, and they will be subtracted from your initial 25 ECUs. You are not prohibited from bidding above your value, but you can ensure that you never make losses as long as you never bid above your value.

You will see, on the second page of your handout, what the winning bidder's screen will look like at the end of a round. Notice that winning bid is equal to your bid. If more than one person submits the same bid, and this is the winning bid, the computer will randomly select a winner from those that were tied. On this handout, your value is 53 , and your bid is 45 , therefore your earnings for the round are $53-45=8$ ECUs $(100$ ECUs $=\$ 4.00)$.

There will be 30 rounds for this portion of the experiment 
Journal of Business \& Economics Research - November 2011

\section{NOTES}

